\title{
INTRASEASONAL VARIABILITY OF GUANO STAINS IN A REMOTELY SENSED PENGUIN COLONY USING UAV AND SATELLITE
}

\author{
M. Firla ${ }^{1}$, O. Mustafa ${ }^{1}$, C. Pfeifer ${ }^{1}$, M. Senf ${ }^{2}$, S. Hese ${ }^{3}$ \\ 1: ThINK - Thuringian Institute of Sustainability and Climate Protection, Germany - firla.maximilian@gmail.com, (osama.mustafa, \\ christian.pfeifer)@think-jena.de \\ 2: Institute of Ecology and Evolution, Friedrich Schiller University Jena, Germany - martin.senf@ uni-jena.de \\ 3: Institute for Geoinformatics, Friedrich Schiller University Jena, Germany - soeren.hese@ uni-jena.de
}

KEY WORDS: Remote Sensing, Breeding phenology, Gentoo penguin, Ardley Island, GEOBIA, Guano

\begin{abstract}
:
Remote sensing of penguins gives a unique opportunity to observe ecosystem changes in the Antarctic and the Southern Ocean at a continent-wide scale. The extent of guano is the best proxy to the size of penguin populations but frequent cloud cover limits the number of available images. This study focuses on the correlation between guano coverage visible in aerial and satellite images and breeding pair numbers in the course of the breeding seasons 2016/17 and 2017/18 in a colony of Pygocelid penguins on Ardley Island (South Shetland Islands, Antarctica). Multitemporal UAV (Unmanned Aerial Vehicle) orthomosaics and high-resolution satellite images were collected of Ardley Island as well as data on breeding phenology, weather conditions and snow coverage. "Fresh" guano stains were classified using different methods of Geographical Object-based Image Analysis (GEOBIA) and differentiated from weathered guano stains. Analysis of this data shows that guano stains in an Antarctic Pygoscelid penguin colony undergo significant intraseasonal changes in extent, texture and spectral signature. Hence, the timing of image acquisition and the advance of snow melt during Antarctic spring matter when determining penguin populations and should be considered during the analysis. Our results show changes of up to $25 \%$ of the total guano covered surface due to individual weather events and changes up to $80 \%$ in the time between the peak of egg laying and the occurrence of the first crèche.
\end{abstract}

\section{INTRODUCTION}

In the last decade, remote sensing data from the Antarctic has been used to detect and quantify penguin colonies, as traditional field methods are too expensive to produce a comprehensive picture. Studies on Emperor penguins (Aptenodytes forsteri) and Adélie penguins (Pygoscelis adeliae) proved remote sensing data can be used for continent-scale penguin populations (Fretwell et al., 2012; Lynch \& LaRue, 2014). While both studies showed that remote sensing data provided a useful tool for penguin population surveys, challenges were also noted. The challenges identified by Lynch et al. (2012) include timing relative to the phenology, topography, nest density and interpreter experience. These are all critical factors for detecting the extent of the guano stains. Mustafa et al. (2017a) found, that the extent of the guano cover in the Maritime Antarctic strongly depends on the advance of the breeding season.

The Goal of this study is to achieve reliability and comparability of results when detecting the extent of guano covered areas using UAV and satellite images acquired at different dates. Therefore, it is necessary to understand the processes that dominate the fluctuations in the extent of guano covered areas during the breeding season. During the breeding seasons $2016 / 17$ and 2017/18, the extent of guano covered areas caused by the penguin colony on Ardley Island was analysed using a multitude of high-resolution satellite and UAV images. The results were set in relation with breeding phenology, in situ breeding pair counts and local meteorological data.should be single-spaced, unless otherwise stated. Left and right justified typing is preferred.

\section{METHODS AND STUDY AREA}

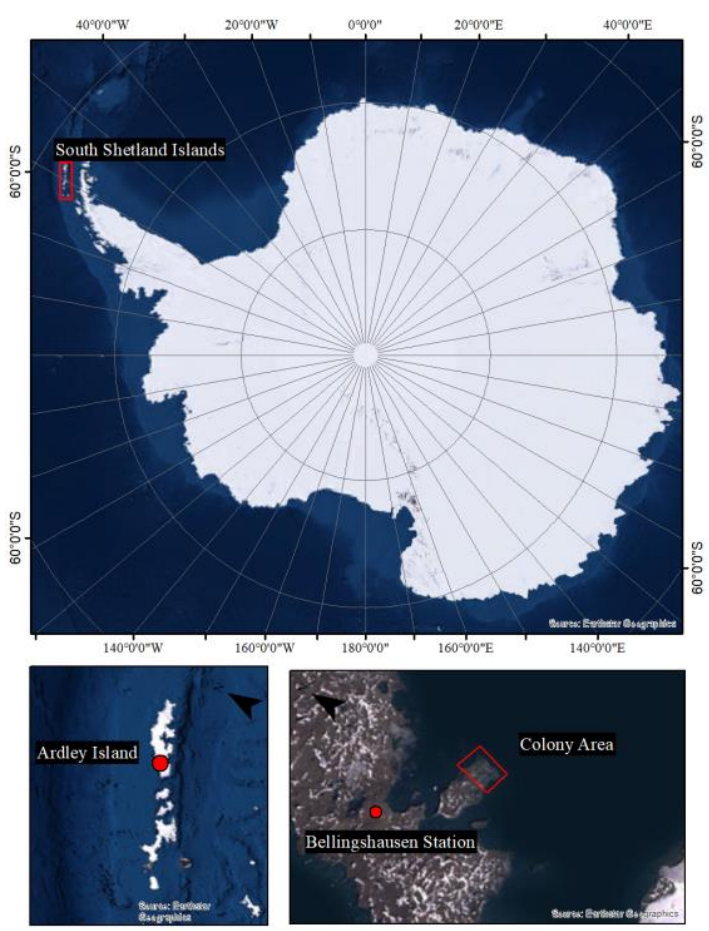

Figure 1. Position of the study area. (C) Earthstar Geographics 2018, NASA, USGS.

\footnotetext{
* Corresponding author
} 
Ardley Island is a $1.2 \mathrm{~km}^{2}$ large tidal island in the South Shetland Islands, which are part of the maritime Antarctic (Figure 1). The study area covers roughly 600 ha, located on the northeastern part of Ardley Island and includes the entire penguin colony of the island. In the $2016 / 17$ season, 7,227 breeding pairs (BP) of gentoo penguins (Pygoscelis papua) and 448 BP of Adélie penguins populated Ardley Island, while in the season 2017/18, only 6,242 BP of gentoo and 305 BP of Adélie were breeding on the island (Senf, 2018).

It is not yet possible to distinguish these penguin species reliably in satellite images. However, since this colony is strongly dominated by Gentoo penguins, the data (e.g. breeding phenology) and statements of this study refer to this species.

Guano in penguin colonies does not have a uniform appearance because the spectral properties of the guano depend on: 1 . the food the penguins consume krill causes pinkish guano, algae greenish, fish white and vomit and bile can cause greenishyellow guano (Rees et al., 2017), and 2. the moisture of the guano which predominantly changes the brightness (Rees et al. 2017). In addition, the appearance of the guano changes when it gets decomposed weathered or mixed with soil (Mustafa et al., 2017b). The classification approaches in this study were applied only to fresh guano, which appears reddish and relatively bright, in contrast to the darker, older guano. To identify the spectral differences between light-coloured, dark-coloured and weathered guano, 50 pixels of each, as well as 50 pixels of soil, were randomly analysed.

\begin{tabular}{lcc}
\hline \multicolumn{1}{c}{ date } & resolutionsor in $m$ & sampeld resolution in m \\
\hline 19-Sep-16 Geoeye & Multi: 2; Pan: 0.5 & 0.5 \\
26-Oct-16 Worldview-2 & Multi: 2; Pan: 0.5 & 0.5 \\
08-Nov-16 Geoeye & Multi: 2; Pan: 0.5 & 0.5 \\
10-Nov-16 Samsung MX500 & 0.02 & 0.2 \\
03-Dec-16 Mapir Survey 2 RGB & 0.033 & 0.2 \\
07-Dec-16 Geoeye & Multi: 2; Pan: 0.5 & 0.5 \\
07-Dec-16 Mapir Survey 2 RGB & 0.021 & 0.2 \\
08-Dec-16 Mapir Survey 2 RGB & 0.022 & 0.2 \\
25-Dec-16 Mapir Survey 2 RGB & 0.024 & 0.2 \\
30-Dec-16 Mapir Survey 2 RGB & 0.025 & 0.2 \\
04-Jan-17 Geoeye & Multi: 2; Pan: 0.5 & 0.5 \\
07-Jan-17 Mapir Survey 2 RGB & 0.026 & 0.2 \\
13-Jan-17 Mapir Survey 2 RGB & 0.025 & 0.2 \\
20-Jan-17 Mapir Survey 2 RGB & 0.027 & 0.2 \\
02-Feb-17 Mapir Survey 2 RGB & 0.026 & 0.2 \\
06-Feb-17 Worldview-2 & Multi: 2; Pan: 0.5 & 0.5 \\
19-Mar-17 Worldview-2 & Multi: 2; Pan: 0.5 & 0.5 \\
24-Oct-17 Phantom 4 PRO & 0.025 & 0.2 \\
27-Oct-17 Phantom 4 PRO & 0.019 & 0.2 \\
01-Nov-17 Phantom 4 PRO & 0.017 & 0.2 \\
08-Nov-17 Phantom 4 PRO & 0.015 & 0.2 \\
20-Nov-17 Phantom 4 PRO & 0.015 & 0.2 \\
07-Dec-17 Phantom 4 PRO & 0.016 & 0.2 \\
22-Dec-17 Phantom 4 PRO & 0.017 & 0.2 \\
27-Dec-17 Worldview-2 & Multi: 2; Pan: 0.5 & 0.5 \\
31-Dec-17 Phantom 4 PRO & 0.017 & 0.2 \\
14-Jan-18 Phantom 4 PRO & 0.016 & 0.2 \\
26-Jan-18 Phantom 4 PRO & 0.019 & 0.2 \\
\hline Tabl. Acquired reno & \\
\hline
\end{tabular}

Table 1. Acquired remote sensing data between 2016 and 2018: Multi: multispectral, Pan: panchromatic data types.
Breeding phenology was determined in accordance with CCAMLR (2014), as described in detail by Senf (2018). UAV systems and cameras changed throughout the two seasons (see Table 1). Meteorological data used in this study was recorded at Bellingshausen Station (rp5.ru, 2018), which is located $3 \mathrm{~km}$ northwest of the study area. Pre-processing of the satellite images included: pan-sharpening, orthorectification and conversion in reflectance values (top of the atmosphere) using the software ArcGIS version 10.5. UAV orthomosaics were created using Agisoft PhotoScan Pro and the geolocation was corrected using data often ground control points. All UAV orthomosaics were sampled to a spatial resolution of $0.2 \mathrm{~m}$. RMS values were $<1.5 \mathrm{~m}$ and the overlap in trajectory was 70 $\%$. In the season 2016/17, UAV orthomosaics and satellite images were analysed using two independent rulesets, while in season 2017/18 the satellite image from December 27 was processed with the ruleset of the UAV orthomosaics of this season.

Breeding phenology of the Ardley Island penguin colony for the seasons 2014/15, 2015/16, 2016/17 and 2017/18 was determined by Senf (2018). The initial event of penguin breeding phenology is when the first nests are created. As the timing of breeding phenology changes between the seasons we used this event for date calibration and set it to the value zero. Days before and after this day get negative respectively positive values. Other distinctive events of the breeding phenology are the peak of egg laying (50\% of all nests have at least one egg; Müller-Schwarze, 1984) and the peak of hatching (50\% of all chicks have hatched; Müller-Schwarze, 1984). Some weeks later, the first crèches form. Both breeding seasons analysed in this study lasted for around 90 days.

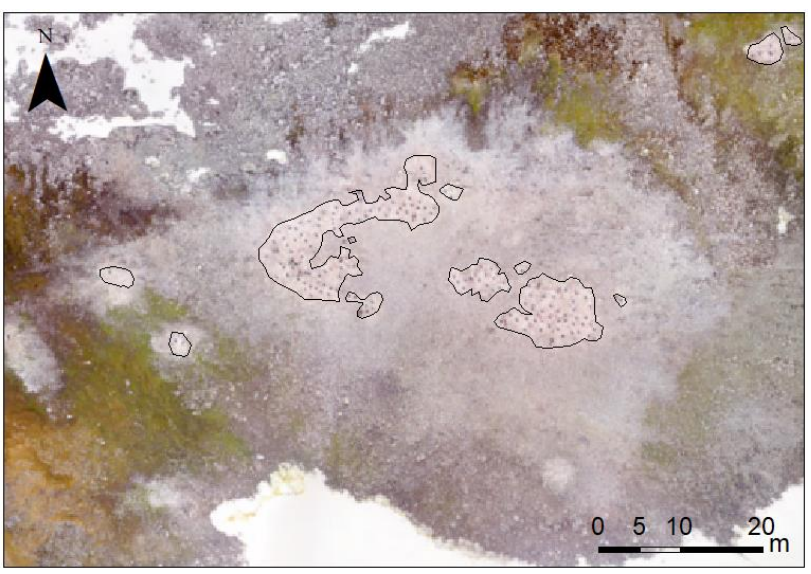

Figure 2. UAV orthomosaic of penguin nest groups showing the areas of fresh guano (inside black polygons).

In order to verify how well various classification approaches distinguish between different guano, we compared two object based classification results. For validation, all guano covered areas were manually delineated using expert- and on-site knowledge. These apply a GEOBIA object oriented approach (Arvor et al., 2013). The selective classification interprets each image separately with its own variables for the segmentation and its own features for the classification. The ruleset classification, uses one fixed set of segmentation variables and classification features for the entire season. In the object-based image analysis software eCognition, a ruleset is a list of algorithms that are applied to a given image. Figure 2 shows only fresh and nonrinsed out guano is examined. This decision 
was made because, on Ardley Island, weather events which rinse out guano occurred in both seasons. However, the goal is to examine the intraseasonal change in guano extent without interference by meteorological effects to get a generalised picture of a season.

To segment the images, a multi-resolution segmentation (MRS) was used. This is the most commonly used method in image segmentation (Baatz \& Schärpe, 2000). The image segmentation was based on spectral differences. Each band can be used with different weighting. The difference between ruleset and selective classification is the used feature and the trained feature space. For the selective classification, each image is evaluated separately. This means own variables for segmentation and the most suitable features. For each, a distinct variable set for segmentation and own features set for classification is chosen. The ruleset was created employing the most common segmentation variables and classification features used in the selective approach. In season 2016/17, different rulesets for satellite and UAV images were used because of differences in spatial resolution and spectral resolution of the available datasets. The classification was performed in five different areas, located strategically in each part of the study region. In both methods, the supervised nearest neighbour classification concept was used. Using only membership functions proved insufficient. Classification results were validated using manually delineated test areas, and compared to temperature, precipitation, snow cover, and breeding phenology.

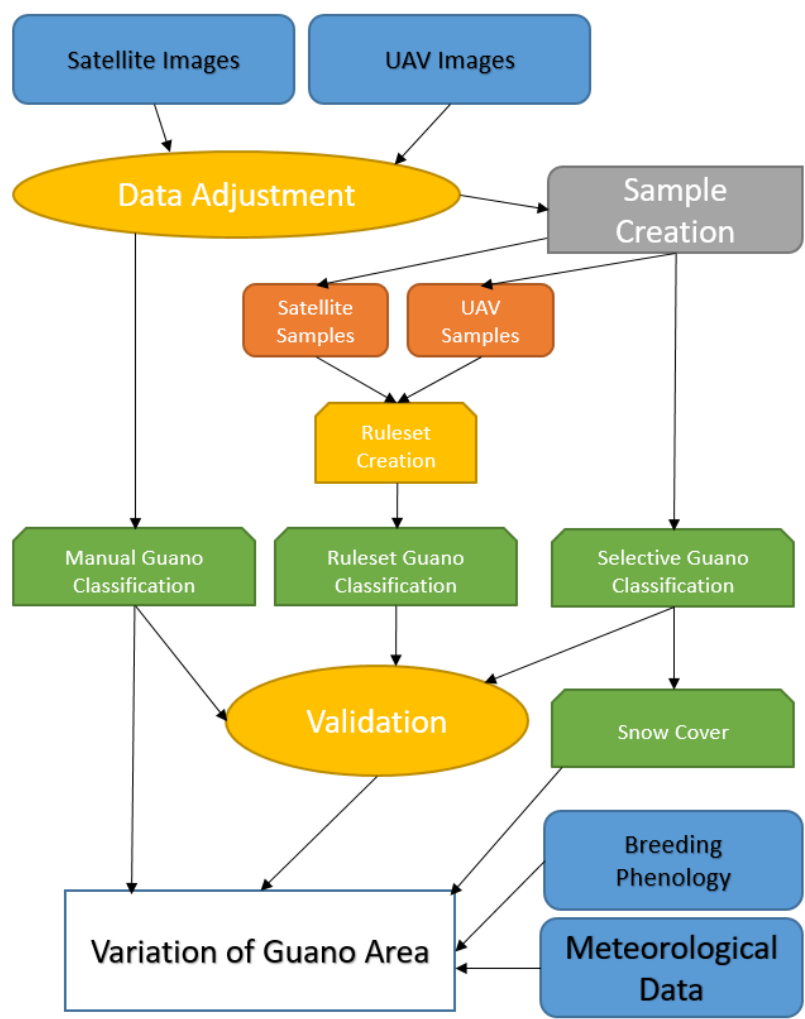

Figure 3. Workflow Diagram

To validate the results the criteria Completeness, Correctness and Quality were used (Cai et al., 2018):

$$
\begin{gathered}
\text { Completeness }=\text { TPTP }+F N \\
\text { Correctness }=\text { TPTP }+F P \\
\text { Quality }=\text { TPTP }+F P+F N
\end{gathered}
$$

Where: $\quad \mathrm{TP}=$ true positive pixels

$\mathrm{FP}=$ false positive pixels

$\mathrm{FN}=$ false negative pixels

\section{RESULTS}

Differences between light-coloured and dark guano are mostly due to varying moisture levels. The different spectral properties are expressed in Figure 4 and visualise the challenge of differentiating guano and soil. Using the Red-Band, the weathered and dark guano cannot be distinguished from the different soils on Ardley. Only the light-coloured guano can clearly be distinguished from soil using Red- and IR-Band.

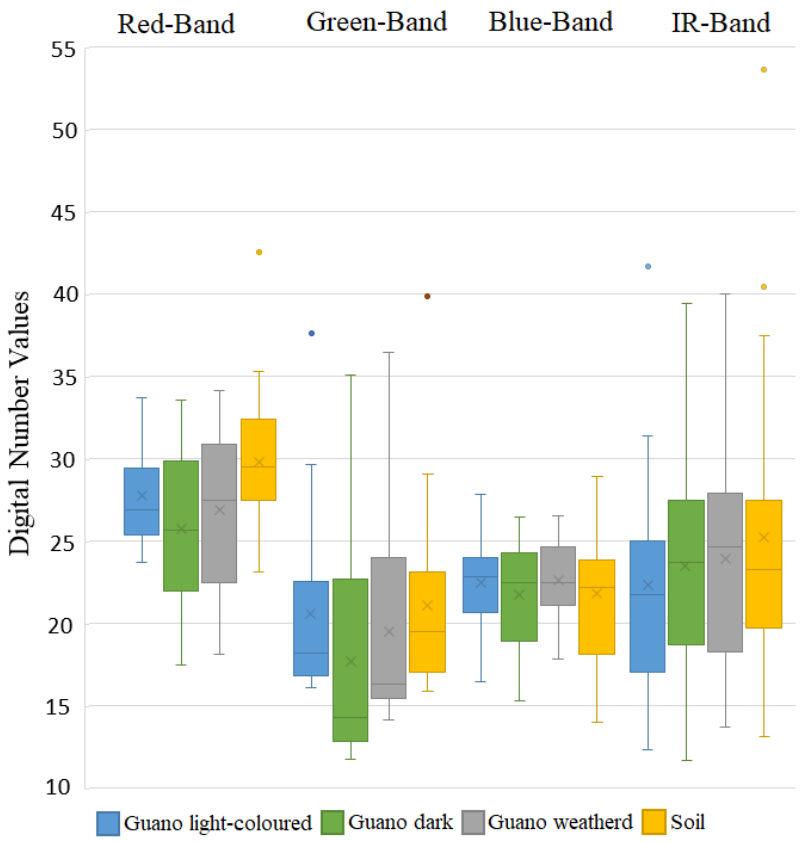

Figure 4. Spectral properties of different ground covers on Ardley Island. IR-Band only available in satellite images. Plot shows outliers (points), min. and max. without outliers (whiskers), quartils (box), median (line in box) and mean (mark in box).

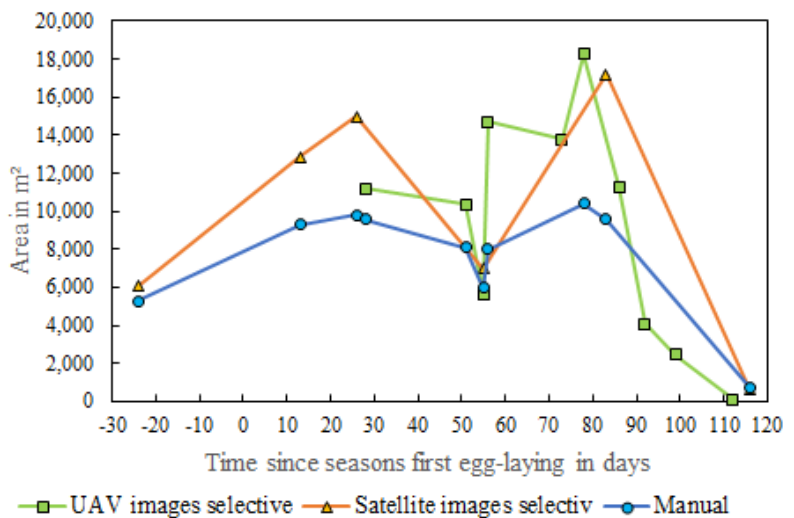

Figure 5. Season 2016/17: different selective classification results.

In season 2016/17, the peak of egg laying occurred ten days after the start of the season. When compared with the classified guano extent (Figure 5) the area reaches its maximum 
expansion 26 days after the season starts. Using selective classification, the classified area in September is only $10 \%$ larger in comparison to the manual classification, in October 40 $\%$ and in November $50 \%$. In comparison, Figure 6 shows a much greater change in the ruleset classification with underclassification on day -24 and 13 and over-classification on day 26. On day 28 , the ruleset classification using a UAV image fits much better with only a slight over-classification in comparison to manual classification. The area classified by all three methods is losing size until day 55. A lack of images in this period makes it a challenge to tell when and how fast the area is diminishing. Figure 9 shows a strong precipitation period at the end of November, which probably strongly influenced the guano extent. Figure 8 shows the guano extent's local minimum is strongly influenced by precipitation especially snow. From day 52 to 55 , the snow cover rises from 32 to $48 \%$, only to decrease from 48 to $30 \%$ in a single day. Around day 55, the results of all classifications are similar to nearly the same expansion. Again, the ruleset classification shows much higher variation. Guano extent increases in size and reaches a second maximum value between day 78 and 83 . At this point, the area decreases fast compared to the abandoning of nests by the penguins (Figure 7). After day 100 (early February) nearly no fresh guano can be classified and it must be noted that new guano stains in beach proximity are found. These originate from the crèches - groups of penguin chicks waiting for their parents to return from the sea with food.

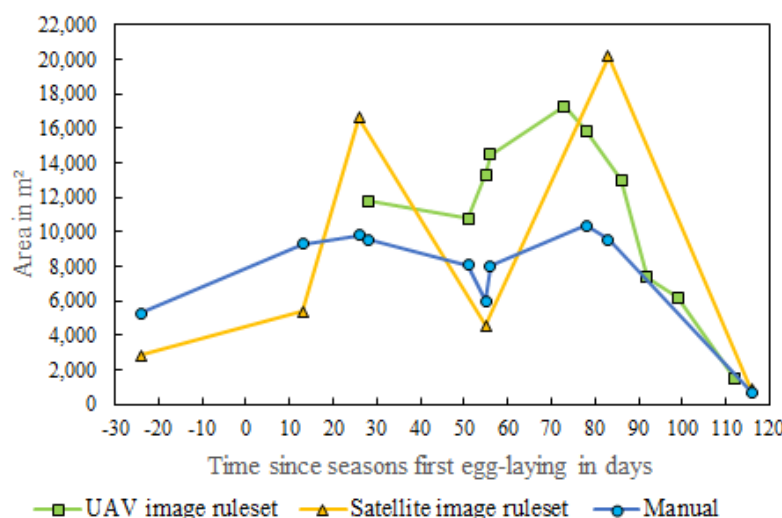

Figure 6. Season 2016/17: different ruleset classification results

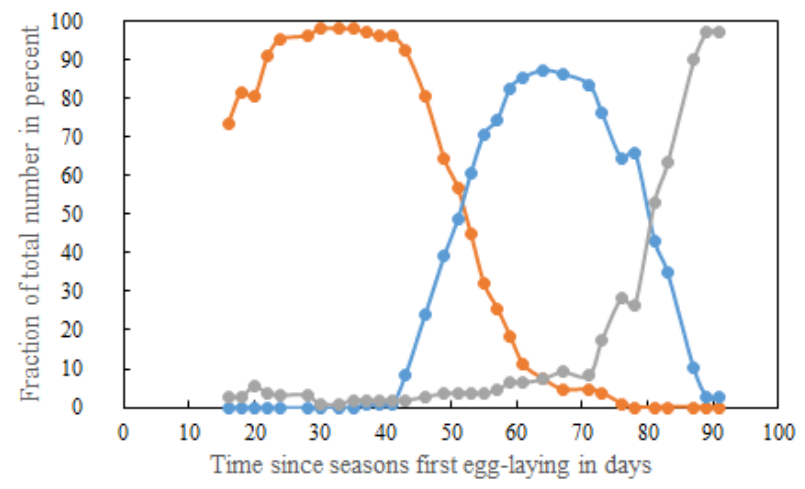

$\longrightarrow$ Nests with eggs $\multimap-$ Nests with chicks $\multimap-$ Nests abandoned

Figure 7. Season 2016/17: breeding phenology of gentoo penguins

Differences between selective, ruleset and manual classification show a large margin in absolute values, but all differences show similarities in their trends. Selective and ruleset classification nearly always over-classify with $50-100 \%$, this is plausible given the imaging challenges. Using available data, it is challenging to explain the differences between selective and ruleset classification around day 28. Differences around day 55 are easier to explain. The satellite image was taken 13:48 GMT while the UAV images were taken 17:51 GMT. During this time, the additional snow cover had already thawed. The guano extent reaches its final maximum for both classifications on day 78 (satellite image) and 83 (UAV image) before decreasing to zero, shortly after nest abandoning and forming of the first crèche on day 73 .

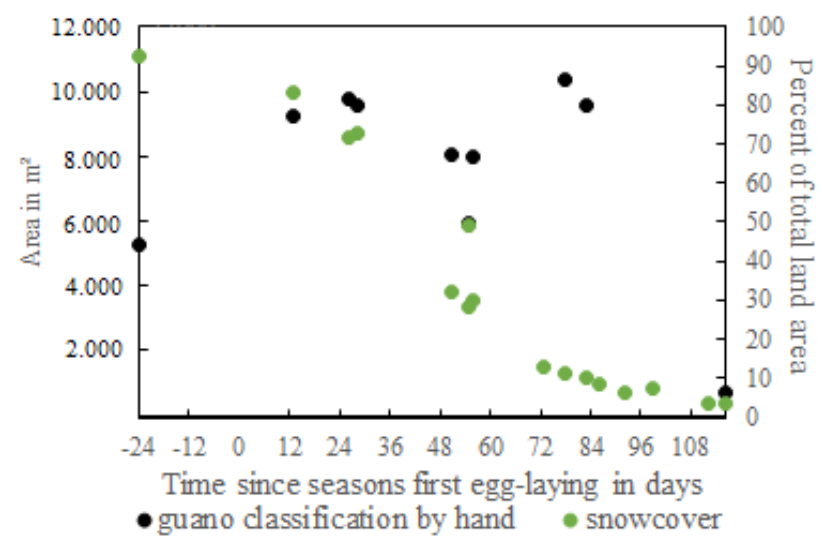

Figure 8. Season 2016/17: connection between snow cover and guano extent. Percent equals total land area in the survey area.

The largest impact on guano extent in season 2016/17 is contributed to: 1. Breeding phenology, which dictates the time frame and principle course. 2 . Snow cover, which seems to have a great influence on guano extent, with strong influence at the beginning and decreasing influence as the season proceeds. 3 . Other influences for example through temperature and moisture.

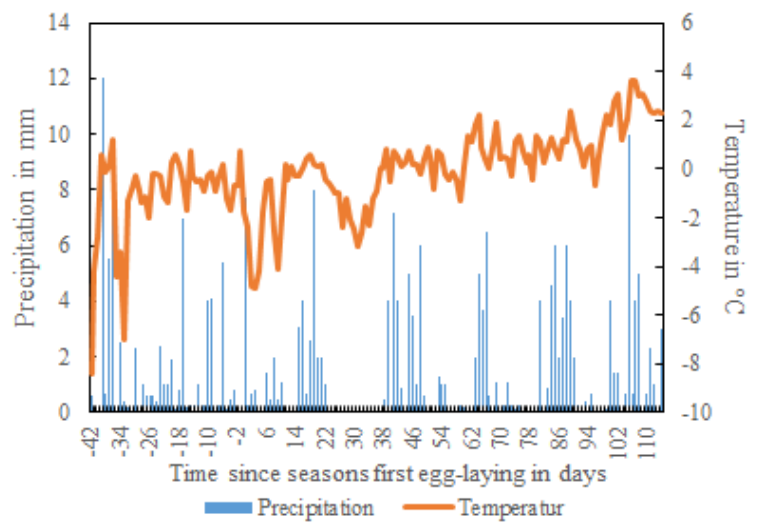

Figure 9. Season 2016/17: precipitation and temperature.. Source: rp5.ru (2018)

Validation results in Table 2, show limited quality of nearly all classifications. Only four out of ten classifications show a quality between 40 and $60 \%$. This is not ideal but explainable by the complex structure of the Ardley Island colony. Nest group sizes vary from one to almost 1,000 nests, the ground is covered by either sand, rock, clay or old decomposed guano, weather effects, different guano colours and different moisture levels caused by precipitation and snow melting. Nevertheless, the overall quality is similar to studies under comparable conditions, e.g. Witharana and Lynch (2016) on Aitcho Island. 
In season 2017/18, the peak of egg laying occurred at day 10 (Figure 11). The beginning of the season, in Figure 10, is marked with a small local minimum at day -1 in the by-hand classification and on day 4 when using the other two methods. These differences were caused by precipitation, particularly snow events. On day -1 , the average daily temperature dropped to $-5.7{ }^{\circ} \mathrm{C}$, on the same day $4 \mathrm{~mm}$ precipitation in form of snow occurred (Figure 13). From this point, the area shows a steady rise until the abandoning of the first nests and occurrence of crèches. In each case, the selective and ruleset method scored a comparable result with $60-100 \%$ (decreasing over time) overclassification. On day 55, the results of both classifications are nearly identical. While the manual classification shows expected results, the two automatic classification results show a strong decrease in area. Reasons for this are not completely understood, but it is possible that rainfall directly before the images were taken had decreased the spectral signature of guano and made it harder for the machine algorithmic to classify guano. Another explanation could be the temperature on day 54 . It was an especially warm day, which could have increased snow thawing, which in turn decreased the spectral signature of guano. On day 60 , the results again show more expected values and reach the absolute maximum of this season, comparable to the high points of season 2016/17. While the ruleset classification shows a strong over-classification, the selective result now decreases and is more in line with the manual classification, with only $10 \%$ over-classification. On day 64 , the guano extent starts to dramatically decrease even when nest abandoning did not completely start until day 72 . It is likely the meteorological event on day 62 with $6 \mathrm{~mm}$ precipitation produced this effect.

\begin{tabular}{|rccc|}
\hline \multicolumn{4}{|c}{ Selective method } \\
Date & Precision & Recall & Quality \\
\hline 19-Sep-2016 & 55.47 & 62.73 & 41.72 \\
26-Oct-2016 & 41.42 & 57.57 & 31.67 \\
8-Nov-2016 & 43.81 & 60.36 & 34.02 \\
10-Nov-2016 & 61.63 & 74.04 & 50.68 \\
3-Dec-2016 & 62.05 & 40.21 & 30.78 \\
7-Dec-2016 & 24.88 & 29.05 & 15.48 \\
8-Dec-2016 & 46.82 & 62.88 & 36.68 \\
30-Dec-2016 & 57.89 & 85.86 & 52.85 \\
4-Jan-2017 & 45.64 & 84.00 & 41.99 \\
6-Feb-2017 & 21.20 & 18.54 & 10.97 \\
\hline & Ruleset method & \\
Date & Precision & Recall & Quality \\
\hline 19-Sep-2016 & 23.58 & 30.85 & 15.43 \\
26-Oct-2016 & 38.90 & 22.71 & 16.74 \\
8-Nov-2016 & 56.99 & 33.64 & 26.83 \\
10-Nov-2016 & 71.68 & 38.15 & 33.15 \\
3-Dec-2016 & 72.51 & 30.21 & 28.13 \\
7-Dec-2016 & 12.98 & 16.97 & 7.94 \\
8-Dec-2016 & 42.71 & 25.25 & 18.86 \\
30-Dec-2016 & 79.38 & 45.22 & 40.47 \\
4-Jan-2017 & 65.42 & 30.97 & 26.62 \\
6-Feb-2017 & 19.04 & 16.06 & 9.54 \\
\hline Table 2. Seas
\end{tabular}

Table 2. Season 2016/17: validation results
Snow cover has a strong correlation with the guano size and even mirrors it except at the end of the season (Figure 12). At the start of the season, a rise in snow cover takes place simultaneous with a decrease in classified guano extent. A steady decrease of snow cover and a steady increase of guano extent are seen until the decrease with abandoning of the nests. In comparison, both seasons showed similar maximum area values at the end of the season but slightly different densities with $10,385 \mathrm{~m}^{2}$ and 7,675 breeding pairs at day 63 with a density of 0.74 breeding pairs per $\mathrm{m}^{2}$ (season 2016/17) in comparison with $11,040 \mathrm{~m}^{2}$ and 6,547 breeding pairs with a density of $0.59 \mathrm{~m}^{2}$ on December 27 (season 2017/18).

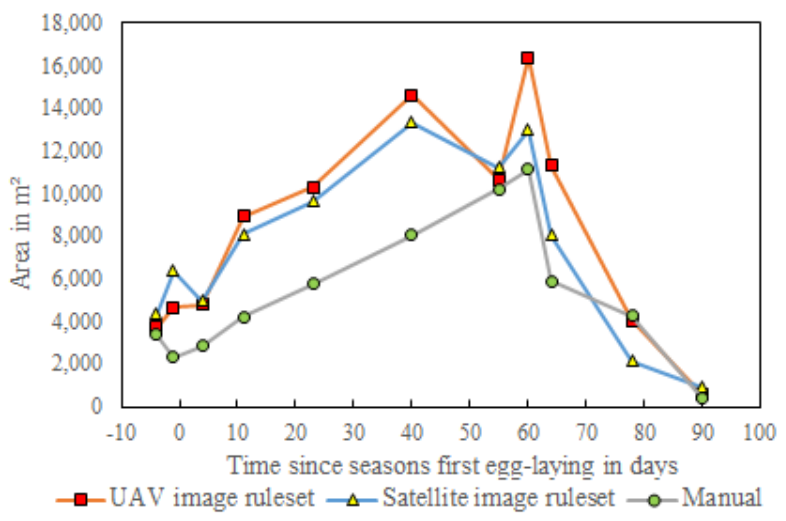

Figure 10. Season 2017/18: different classification results

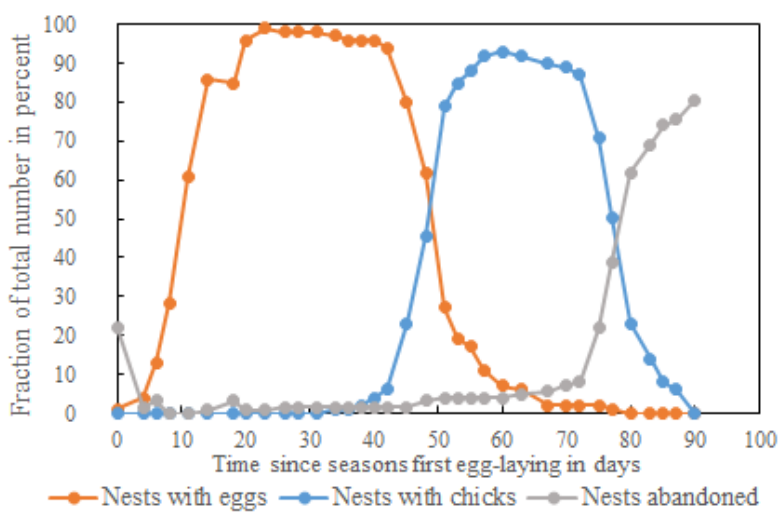

Figure 11. Season 2017/18: breeding phenology of gentoo penguins

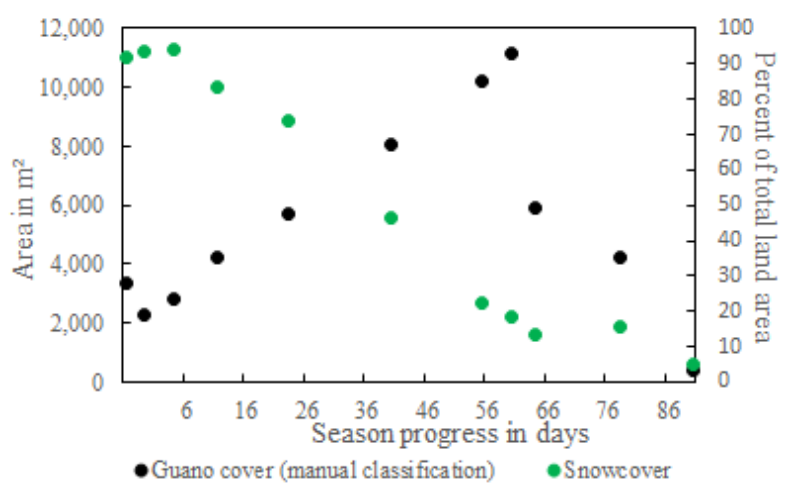

Figure 12. Season 2017/18: comparison between snow cover and guano extent. Percent equals total land area in the survey area. 
Same as in season $2016 / 17$, the quality of the classification is poor. In this season, only one in eleven images shows a quality of over $40 \%$. Why this season shows even poorer results is difficult to tell. The highly irregular nature of guano could be at fault, which increases the chance of incorrect classifications.

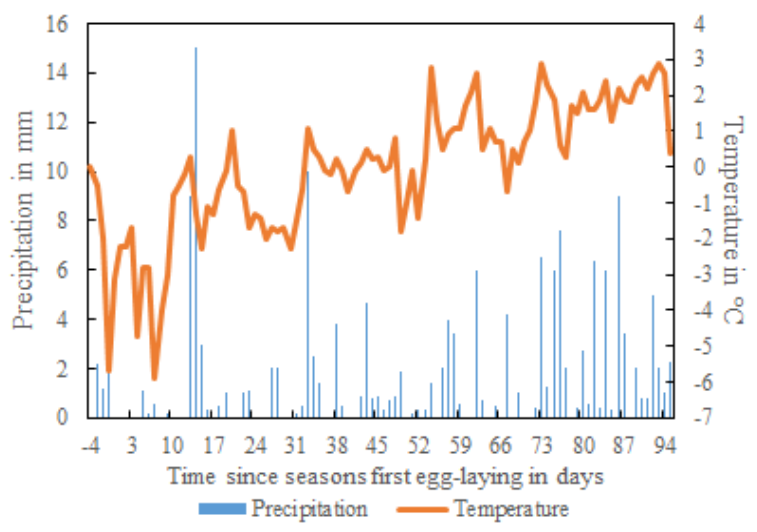

Figure 13. Season 2017/18: precipitation and temperature. Source: rp5.ru (2018)

\begin{tabular}{|c|c|c|c|}
\hline \multicolumn{4}{|c|}{ Selective method } \\
\hline Date & Precision & Recall & Quality \\
\hline 24-Oct-2017 & 46.43 & 41.38 & 28.01 \\
\hline 27-Oct-2017 & 81.11 & 36.54 & 33.67 \\
\hline 1-Nov-2017 & 60.08 & 40.81 & 32.67 \\
\hline 8-Nov-2017 & 53.87 & 28.59 & 22.96 \\
\hline 20-Nov-2017 & 58.30 & 29.64 & 24.46 \\
\hline 7-Dec-2017 & 69.26 & 45.42 & 37.80 \\
\hline 22-Dec-2017 & 66.78 & 47.37 & 38.34 \\
\hline 27-Dec-2017 & 65.54 & 49.27 & 38.09 \\
\hline 31-Dec-2017 & 64.25 & 48.23 & 38.03 \\
\hline 14-Jan-2018 & 66.88 & 61.04 & 46.87 \\
\hline 26-Jan-2018 & 63.11 & 26.40 & 22.87 \\
\hline \multicolumn{4}{|c|}{ Ruleset method } \\
\hline Date & Precision & Recall & Quality \\
\hline 24-Oct-2017 & 42.31 & 38.15 & 25.25 \\
\hline 27-Oct-2017 & 69.62 & 35.07 & 30.42 \\
\hline 1-Nov-2017 & 51.59 & 31.08 & 24.06 \\
\hline 8-Nov-2017 & 46.13 & 25.53 & 19.67 \\
\hline 20-Nov-2017 & 39.49 & 22.11 & 16.52 \\
\hline 7-Dec-2017 & 63.31 & 35.16 & 29.21 \\
\hline 22-Dec-2017 & 47.41 & 46.36 & 30.62 \\
\hline 27-Dec-2017 & 52.42 & 40.95 & 27.91 \\
\hline 31-Dec-2017 & 50.03 & 36.15 & 26.56 \\
\hline 14-Jan-2018 & 80.81 & 60.15 & 52.63 \\
\hline 26-Jan-2018 & 20.97 & 14.27 & 9.28 \\
\hline
\end{tabular}

Table 3. Season 2017/18: validation results

Differences between both seasons are greatest at the beginning of each. While in season 2016/17, there are two high points in the area at the peak of egg laying +10 and before the abandoning of the nest, season 2017/18 only has one before the abandoning. The most likely reason for this difference is the amount of snow cover. As seen in Figure 14, the absolute snow cover in season $2016 / 17$ was nearly $10-20 \%$ lower than in Season 2016/17. The explanation for this can be found in September and October temperatures. Figure 15 shows how in the 2016/17 season, temperatures in September and October reached values above $0{ }^{\circ} \mathrm{C}$ several times and started the thawing process early, while in season 2017/18 the temperatures stayed under $0{ }^{\circ} \mathrm{C}$ until the middle of October. This could also be important for the breeding phenology. In season 2016/17, the peak of egg laying occurred two weeks earlier than in season 2017/18. This two-week shift is also observed in the timing of nest abandoning in season 2016/17 it began on December 23 (day 71), while in the later season it started on January 8 (day 72). While both events start around the same time relative to the breed phenology, the absolute date is nearly two weeks apart. Looking at the date, it should be noted season 2017/18 reaches nearly zero guano area within only three weeks, while in season $2016 / 17$, it took a month. Why the decrease is faster and started even before the nest abandoning, cannot be explained using the present data. Breeding phenology is a likely cause. Both seasons lasted the same amount of time 90 days. Because of this, it is possible that the later and slower beginning of the breeding season in 2017/18 (15 days later than in season 2016/17) forced the penguins to hasten the nest abandoning towards the end.

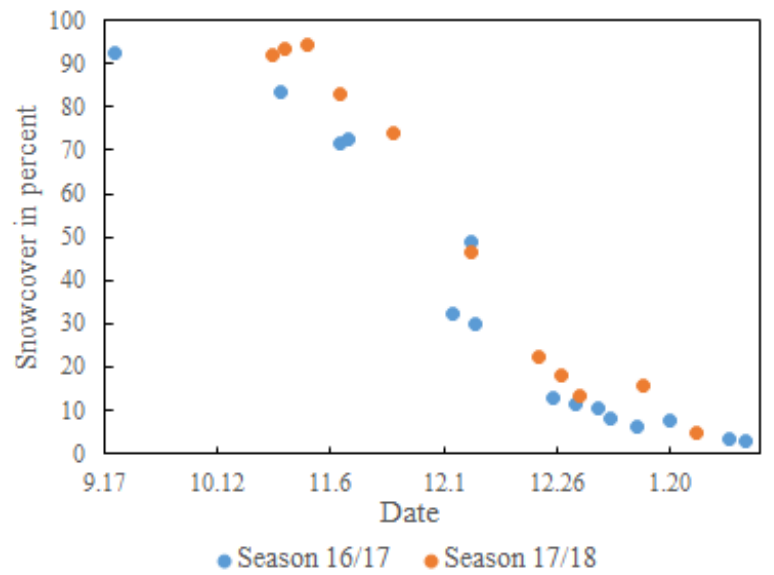

Figure 14. Season 2016/17 and 2017/18: snow cover. Percent equals total land area in the survey area.

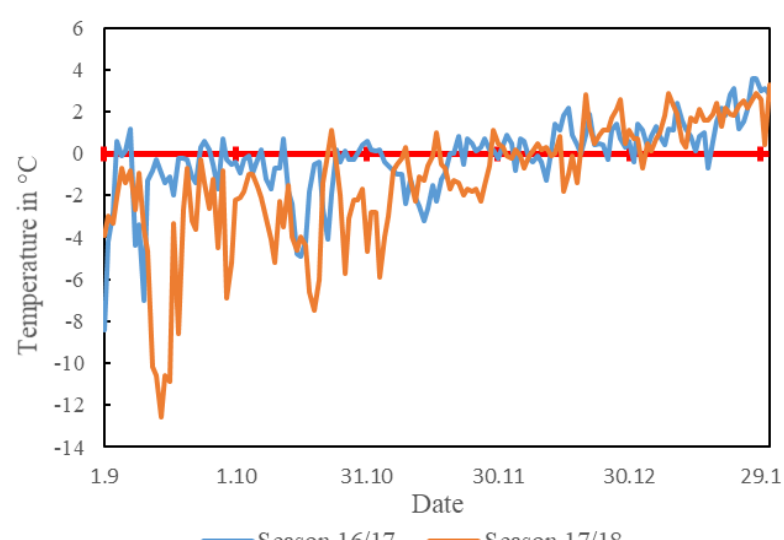

Figure 15. Season 2016/17 and 2017/18: temperatures. Source: rp5.ru (2018). 


\section{DISCUSSION}

It should be noted that it is difficult to create expert knowledgebased reference data for this study. Since classification and validation are based on the same expert knowledge-derived reference data, an intrinsic error might be included. This is mainly because of the complex topography of Ardley Island and the penguin colony there. In short, the impact of user error cannot be estimated and could be significant. The main problems can be summarized as follows: 1. Different ground covers of Ardley Island, some degradation products of guano, mess with the ability to distinct guano from other ground covers. 2. Guano has not one unique spectral signature, which increases difficulties to accurately classify it 3 . Sizes of nest groups are difficult to determine. While some groups include $100-1,000$ nests there are also nest groups with only $1-10$ nests. Detecting both sizes equally well is a challenge. 4 . Though meteorological data from Bellingshausen station is available and the station is located only $3 \mathrm{~km}$ away from the site, the acquired data does not necessarily reflect the factual reality on Ardley. For example, the snow event in season $2016 / 17$ on December 7 is not reflected by the data. 5. Only data of two seasons was available and these seasons show significant differences in some aspects. Nevertheless, the focus of this work is not the absolute guano state throughout the season, but the relative change of it.

From our results, it is evident that both seasons show similar characteristics. For example, date of beginning and end of season determine the date when guano extent increases and decreases. Differences of both seasons were at peak of egg laying +10 were in season 2016/17 a local maximum of area extent was reached while in season $2017 / 18$ only a slow increase occurred. Afterwards, the data differs as in season $2016 / 17$, a local minimum area was reached while in season $2017 / 18$, the area steadily increased in size. Both seasons show similarities at the first crèche with similar area size, after which both steadily decline until they reach nearly zero guano extent in three to four weeks. Snow cover in both cases had a great effect on the classified area, with more importance early on in the season.

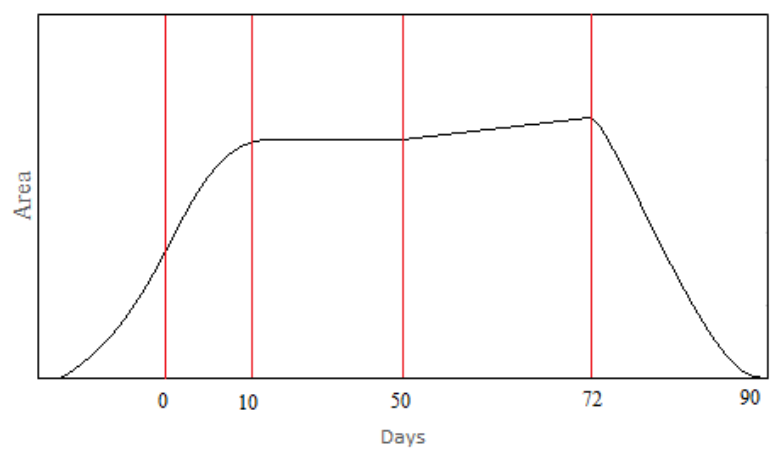

Figure 16. Generalized intraseasonal guano extent change. Peak of egg laying on day 0 . Constant area after day 10. Peak of

Hatching on day 50. First crèche on day 72. End of season on day 90 .

Figure 16 shows a first attempt to set up a generalised representation of the intraseasonal change from the available data. Looking at meteorological data from the last decade, it becomes clear that season 2016/17 was unique, as thaw had already begun in September and October. It could be theorized that because of this, season 2016/17 had a lesser snow cover and was only moderately influenced by snow cover especially at the beginning of the season. In this season, the only considerably large influence was at the local minimum in December, but beginning and end should represent the absolute state. In season 2017/18, steady increase of guano size could potentially be directly connected to thawing. At peak of egg laying, a sizeable amount of guano was covered by snow or directly bordered on snow. When the snow melts, water washes guano out. At the end of the season, guano extent decreases even before the abandoning in connection to an intense rain event. Therefore, it could be argued guano can easily be washed out. So the steady increase in season 2017/18 likely means that the guano extent already reached its absolute maximum but the snow cover in connection with meltwater only allowed for a slow and steady increase.

A small increase after the peak of hatching is speculation using available data. Looking at data from season 2016/17, it appears there is a small increase of guano extent between peak hatching and the first crèche. It is possible that the gunao layer increases in thickness over time which increases the ability to classify it. Secondly, after peak of hatching, there are more penguins in the area, producing more guano. Thirdly, penguins begin to move around more, with chicks taking their first steps and adults not being bound to the egg.

Meteorological conditions always pose a strong influence on guano extent, which can create great differences between peak of egg laying +10 and first crèche, appearing even when the theoretical area should be relatively constant.

\section{CONCLUSIONS}

In this study, the detectability of intraseasonal changes in the extent of penguin guano was investigated. For this purpose, the two seasons' satellite and UAV data was classified and compared with breeding phenology, temperature, precipitation and snow cover.

The main outcomes of this study are:

1. Breeding phenology gives the basic framework for the variability of penguin guano. With the beginning of the nest building, the guano covered area increases. $10-12$ days after the peak of egg laying, it reaches a first maximum. After hatching of the first chicks, guano extent increases slightly and, as soon as the first penguins leave the nests, visible guano extent decreases until a few weeks later the guano has disappeared.

Towards the end of both seasons, guano extent reaches the same absolute maximum around the same date. Because the number of breeding pairs are in a similar magnitude in both seasons, the end of December (before the formation of créches) appears to be the ideal period to detect guano extent. It seems to be uninfluenced by the remaining snow cover and shows the same derived nest density even despite different courses during the seasons. After reaching the maximum area coverage, both show a similar trend decreasing the area in three to four weeks to nearly zero.

2. Precipitation and particularly snow cover induce by far the largest modifications of the general intraseasonal guano extent change (compare Figure 16 with Figure 6 and 12). Particularly at the beginning of the seasons, heavy snow cover may considerably reduce the classifiability of guano. The covering 
influence of snow decreases during the season while the rinsing influence of melt water increases.

Classification of penguins using UAV images is theoretically possible, but not feasible for large areas. Guano extent is much more feasible. Both used classifications show similar but not identical results. The selective classification creates better results while requiring more work to create. The classification Method should be chosen based on available data.

3. Quantifying penguin colonies from guano extent classified in remote sensing data requires more than the application of an average nest density value. To derive comparable datasets for different seasons and different colonies, a deeper understanding of the relation between image acquisition and the course of the breeding season regarding breeding phenology and meteorology is needed.

4. It turned out, that it is possible to record the same trend of guano coverage development in high resolution imagery with the two GEOBIA classifications as with the manual validation. This makes that object-based approach promising for remote sensing of large penguin colonies were a manual classification reaches its limits. The relatively low validation results (Table 1 and 2) may result from the complex structure of this colony. High scattering of very small nest groups hinders classification efforts. But potential fine tuning of the classification algorithm could increase quality.

For the improvement of the methods to quantify penguin guano we identified the following challenges: 1. Overlapping signatures (compare with Figure 2 and 4), 2. High variability in the meteorological conditions with precipitation events, 3 . Mixed spectral signatures of guano covered rock (soil) surfaces types (2.), 3. low data availability about the local breeding phenology for the corresponding seasons.

Spectral and spatial resolution of satellite remote sensing data is sufficient to classify guano extent but mostly due to cloud cover the overall data acquisition frequency is not high enough. In Season 2016/17 the study area was often cloud free and satellite data acquisition frequency was higher than under normal circumstances. In the future more satellite systems for better coverage are needed, for example Planet, while UAV systems should be used to cover missing satellite data. For data about breeding phenology in this latitudes will be likely heavily reliant on local stationary systems, while it possible could also be used for snow cover or precipitation events.

\section{ACKNOWLEDGMENTS}

This study is commissioned by the Umweltbundesamt/ German Federal Environment Agency and funded by the Ministry for the Environment, Nature Protection and Nuclear Safety (FKZ): 3716182100 ). We would like to thank the personnel of the Russian Antarctic Station Bellingshausen for accommodation and support during our expedition.

Logistic support was kindly provided by Alejo Contreras and Aerovias DAP on-site and by Alfred-Wegener-Institute, in general.

\section{REFERENCES}

Arvor, D., Durieux, L., Andrãs, S. \& Laporte, M., 2013. Advances in geographic object-based image analysis with ontologies: A review of main contributions and limitations from a remote sensing perspective. ISPRS J. Photogram. Remote Sens. 2013, 82, pp. 125-137.

Baatz, M. \& Schäpe, M., 2000. Multiresolution segmentation An optimization approach for high quality multi-scale image segmentation. In Angewandte Geographische InformationsVerarbeitung XII; Strobl, J., Blaschke, T., Griesebner, G., Eds.; Wichmann Verlag: Karlsruhe, Germany, 2000, pp. 12-23.

CCAMLR, 2014. CCAMLR Ecosystem Monitoring Program: Standard Methods for Monitoring Studies. Hobart, Australia.

Fretwell, P.T., Larue, M.A., Morin, P., Kooyman, G.L., Wienecke, B., Ratcliffe, N., Fox, A.J., Fleming, A.H., Porter, C. \& Trathan, P.N., 2012. An emperor penguin population estimate: the first global, synoptic survey of a species from space. PloS one 7. p. e33751.

Cai, L., Shi, W., Miao, Z. \& Hao, M., 2018. Accuracy Assessment Measures for Object Extraction from Remote Sensing Images. Remote Sensing 2018, 10, 303.

Lynch, H.J. \& LaRue, M.A., 2014. First global census of the Adélie Penguin. The Auk 131. pp. 457-466.

Lynch, H.J., White R., Black A.D., Naveen R., 2012. Detection, differentiation, and abundance estimation of penguin species by high-resolution satellite imagery. Polar Biol (2012) 35, pp. $963-$ 968.

Müller-Schwarze, D. 1984. The Behavior of Penguins: Adapted to Ice and Tropics. State University of New York Press, Albany.

Mustafa, O., Esefeld, J., Peter, H.-U., Pfeifer, C., 2017a. Does timing matter? Detecting breeding pair numbers of penguins by UAV at different dates of a breeding season. XIIth SCAR Biology Symposium. Leuven, Belgium 10-14 July 2017.

Mustafa, O., Esefeld, J., Grämer, H., Maercker, J., Rümmler, M.-C., Pfeifer, C., 2017b. Monitoring penguin colonies in the Antarctic using remote sensing data (Final Report No. 002498/ENG), Texte 30/2017. German Environment Agency, Dessau-Roßlau.

Reese, W.G., Brown, J.A., Fretwell, P.T. \& Trathan, P.N., 2017. What colour is penguin guano? Antarctic science. 29, 5, pp. 417-425.

rp5.ru, 2018. Weather Archive in Bellinghausen Station. https://rp5.ru/Weather_archive_in_Bellingshausen_Station. Accessed: 04.19.18.

Senf, M., 2018. Brutphänologie von Pinguinen der Gattung Pygoscelis auf der Insel Ardley. Master Thesis Universität Jena, Institut für Ökologie und Evolution.

Witharana, C \& Lynch, H. J., 2016. An Object-Based Image Analysis Approach for Detecting Penguin Guano in very High Spatial Resolution Satellite Images. Remote Sensing 2016, 8, 375. 